\title{
Percepções e práticas dos diretores e coordenadores acerca da alimentação infantil em creches públicas do município de Jandira, São Paulo, Brasil
}

\author{
Fernanda Christina Moreira Marinho ${ }^{1}$, Tatiana Yuri Assao ${ }^{2}$, Ana Maria Cervato-Mancuso ${ }^{3}$
}

A creche tem importante função de promover alimentação saudável, já que é nos primeiros anos de vida que a criança estabelece seus hábitos alimentares. Este estudo examina as práticas e percepções dos gestores de creches sobre alimentação saudável para crianças. Foram realizadas entrevistas com 11 gestores de creches de Jandira, SP. A análise foi elaborada pela metodologia do Discurso do Sujeito Coletivo (DSC) e pelo software Quali Quanti Soft. Os gestores citaram alguns itens que compõem uma alimentação saudável, mas não foram contemplados itens como ambientes das refeições e satisfação das necessidades emocionais. Observou-se também uma lacuna entre aqueles que cuidam da alimentação e educadores. Verifica-se a necessidade de ampliar a abordagem do tema alimentação entre os profissionais do ensino. É preciso que ocorra uma aproximação entre educadores e os profissionais da alimentação, para que eles se tornem promotores de hábitos alimentares saudáveis.

Palavras-chave: alimentação infantil, gestores, creches, pesquisa qualitativa.

\section{Perceptions and practices of directors and coordinators of public day care centers about infant feeding in Jandira, São Paulo, Brasil}

It is in early life that children establish their habits and food preferences, and day care centers have an important role in promoting healthy eating. This study examines practices and perceptions of managers of kindergartens of Jandira, SP, on healthy eating for children. This study was accomplished through individual interviews with 11 managers. The organization and analysis were made through the methodology of the Collective Subject Discourse (DCS) and the software Quali Quanti Soft. The managers cited many items that compose a healthy diet, but were no items covered like the meal environments, the need for an emotional satisfaction associated to the food. It was possible to observe a gap between those who tend the meals and the educators. A need was detected to bridge the gap between the food issue and educators. It is also necessary to bring together both educators and School Meal Program teams to stimulate their participation in the promotion of healthy eating.

Key-words: infant feeding, managers, day care centers, qualitative study.

\section{INTRODUÇÃO}

A creche faz parte da vida diária de muitas crianças. Nas últimas décadas vem aumentando o número de creches e de crianças nelas atendidas. Isso se deve a ampliação da participação das mulheres no mercado de trabalho, a modificação na organização e na estrutura familiar e, em especial, aos avanços na concepção sobre o desenvolvimento e educação infantil [1].

A creche deve ser um ambiente educativo, onde a criança possa ser estimulada e se desenvolver. Para Focesi [2], o ambiente escolar pode ser utilizado para programas de educação em saúde colaborando para o desenvolvimento de uma consciência crítica, que

\footnotetext{
${ }^{1}$ Nutricionista pela Faculdade de Saúde Pública, Universidade de São Paulo (USP).

${ }^{2}$ Doutoranda, Faculdade de Saúde Pública, Universidade de São Paulo (USP).

${ }^{3}$ Profa. Dra. Faculdade de Saúde Pública (USP). Departamento de Nutrição.

Correspondência: Av. Doutor Arnaldo, 715, CEP 01246-904, Cerqueira César, SP. E-mail: cervato@usp.br
} 
resulta na aplicação de práticas para a promoção, manutenção e recuperação da saúde da criança e da comunidade da qual faz parte, bem como, capacitá-la a reivindicar meios para a sua melhoria. Então, entendese que a creche exerce papel fundamental na aquisição de práticas saudáveis, dado que é durante a infância que ocorre o estabelecimento desses hábitos. Assim, essas instituições passam a ter a importante função na promoção de hábitos alimentares saudáveis, visto que as refeições diárias e as práticas socioeducativas das crianças são realizadas nesse ambiente.

Pensando nisso, o Ministério da Saúde e o Ministério da Educação instituíram diretrizes para a Promoção da Alimentação Saudável em escolas de educação infantil, ensino fundamental e médio, das redes pública e privada, em âmbito nacional. O texto da Portaria Interministerial $\mathrm{n}$ ㅇ 1.010 , de 8 de maio de 2006 [3], em que se encontram essas diretrizes, destaca a situação do país, considerando que o padrão alimentar brasileiro está direcionado para uma alimentação densamente calórica, rica em açúcar e gordura, e pobre em fibras. Deste modo, diretrizes foram propostas com a finalidade de desenvolver ações para garantir a promoção da saúde e de práticas alimentares mais saudáveis, para que ocorram mudanças nesse quadro. Para atingir estas diretrizes são estabelecidas ações que devem ser realizadas sob a responsabilidade das escolas.

No Artigo 5o são relatadas ações para que se alcance a alimentação saudável no ambiente escolar. São elas:

I - definir estratégias, em conjunto com a comunidade escolar, para favorecer escolhas saudáveis;

II - sensibilizar e capacitar os profissionais envolvidos com alimentação na escola para produzir e oferecer alimentos mais saudáveis;

III - desenvolver estratégias de informação às famílias, enfatizando sua co-responsabilidade e a importância de sua participação neste processo;

IV - conhecer, fomentar e criar condições para a adequação dos locais de produção e fornecimento de refeições às boas práticas para serviços de alimentação, considerando a importância do uso da água potável para consumo;

$\mathrm{V}$ - restringir a oferta e a venda de alimentos com alto teor de gordura, gordura saturada, gordura trans, açúcar livre e sal e desenvolver opções de alimentos e refeições saudáveis na escola;
VI - aumentar a oferta e promover o consumo de frutas, legumes e verduras;

VII - estimular e auxiliar os serviços de alimentação da escola na divulgação de opções saudáveis e no desenvolvimento de estratégias que possibilitem essas escolhas;

VIII - divulgar a experiência da alimentação saudável para outras escolas, trocando informações e vivências;

IX - desenvolver um programa contínuo de promoção de hábitos alimentares saudáveis, considerando o monitoramento do estado nutricional das crianças, com ênfase no desenvolvimento de ações de prevenção e controle dos distúrbios nutricionais e educação nutricional; e

$\mathrm{X}$ - incorporar o tema alimentação saudável no projeto político pedagógico da escola, perpassando todas as áreas de estudo e propiciando experiências no cotidiano das atividades escolares.

Segundo Philippi et al. [1],

Alimentação saudável é aquela planejada com alimentos de todos os tipos, de procedência conhecida, de preferência naturais e preparados de forma a preservar o valor nutritivo e os aspectos sensoriais. Os alimentos devem ser qualitativa e quantitativamente adequados ao hábito alimentar, consumidos em refeições, em ambientes calmos, visando a satisfação das necessidades nutricionais, emocionais e sociais, para promoção de uma qualidade de vida saudável (2000, p. 47).

No estudo de Assao [4], as percepções e práticas dos educadores acerca da alimentação saudável demonstram-se deficientes quando comparadas aos parâmetros da promoção dos hábitos alimentares saudáveis. Fato também observado por Marinho [5] ao analisar estudos a respeito das percepções sobre alimentação saudável entre profissionais da saúde e da educação.

Os gestores da educação, que são profissionais que buscam integrar a dimensão educativa, o compromisso político e a competência técnica na administração da escola, têm o compromisso de, segundo Reis [6], realizar e executar o projeto educacional, em busca de um ensino de qualidade pela participação de todos que estão inseridos neste contexto. Estes profissionais têm o papel, com a 
autonomia do cargo, de colocar em prática o projeto pedagógico pré-estabelecido e elaborar atividades que auxiliem o processo de ensino e aprendizagem. Tem, também, a função de indicar atividades pedagógicas, com diferentes temas como Alimentação Saudável, e cobrar a presença delas junto aos educadores.

Com a finalidade de contribuir para o aprimoramento da promoção de práticas alimentares saudáveis no ambiente escolar, realizou-se o presente estudo com o objetivo de analisar as percepções e práticas dos diretores e coordenadores de creches acerca da alimentação infantil.

\section{METODOLOGIA}

Neste estudo foi utilizada a abordagem qualitativa e realizado por meio de entrevistas individuais. A metodologia qualitativa, segundo Minayo [7] e Lefèvre et al. [8] é aquela capaz de incorporar as questões do significado e da intencionalidade como inerentes aos atos, às relações e às estruturas sociais. Permitem a compreensão mais profunda dos campos sociais e dos sentidos neles presentes, na medida em que remetem a uma teia de significados, de difícil recuperação por meio de estudos de corte quantitativo, onde o discurso, quando está presente, é sempre reduzido a uma expressão numérica.

A população de estudo foi composta por diretores e coordenadores das creches públicas de Jandira (denominados gestores locais). Este município está localizado a $30 \mathrm{~km}$ de São Paulo e em 2005, estimava-se ter 109.782 habitantes [9]. A Prefeitura Municipal possui 8 escolas de Educação Infantil que englobam o Maternal I e II, e que no ano de 2007, de acordo com o censo escolar do município, foram realizadas 718 matrículas nas creches municipais, que atendem crianças de 0 a 4 anos de idade, em período integral, das $8 \mathrm{~h}$ às $18 \mathrm{~h} \mathrm{[10].}$

Quanto à alimentação das crianças, são realizadas nas creches três refeições principais e dois lanches: café da manhã - 8h30min; lanche da manhã 10h; almoço - 11h30min; lanche da tarde - 13h30min; e jantar $-15 \mathrm{~h}$. As refeições oferecidas pela creche são preparadas pelas cozinheiras e auxiliares de cozinha, essas últimas também lactaristas, responsáveis por manipular o leite oferecido as crianças.

Participaram do estudo os gestores das 8 creches que atendiam o município: 8 diretores de unidades escolares e 3 coordenadores pedagógicos, que tinham por responsabilidade gerir a instituição educacional, identificando as necessidades dos alunos e professores e buscando soluções que priorizem um trabalho educacional de qualidade.

A coleta de dados foi realizada por meio de entrevista, por um nutricionista treinado para este fim. $\mathrm{Na}$ primeira parte da entrevista, constaram questões relativas aos dados pessoais (nome, data de nascimento, gênero, escolaridade e número de filhos), situação econômica (renda individual). Para a segunda parte da entrevista, referente às práticas e percepções, utilizou-se um roteiro com 4 perguntas abertas:

Para você, o que seria uma alimentação saudável para as crianças de 2 a 4 anos?

Existem algumas crianças que se alimentam de forma saudável e outras nem tanto. Como você trabalha com essas diferentes situações aqui na creche?

Considerando a sua experiência, quais atividades você acha que dariam certo para trabalhar a alimentação saudável das crianças? Fale um pouco sobre isso.

Em sua opinião, os monitores desta creche estão capacitados para trabalhar com atividades de alimentação saudável com as crianças? Fale um pouco sobre isso.

A partir das informações pessoais dos entrevistados foi feita a caracterização da população estudada, quanto à idade, escolaridade, filhos e renda individual.

A técnica utilizada para organizar e analisar as respostas foi a do Discurso do Sujeito Coletivo (DSC). A partir do material coletado, fez-se a transcrição literal das respostas das questões, analisando-as segundo o DSC, que se embasa na teoria das Representações Sociais.

A técnica do DSC consiste numa forma nãomatemática, nem metalinguística, de representar o pensamento de uma coletividade, o que se faz mediante uma série de operações sobre os depoimentos, que culmina em discursos-síntese que reúnem respostas de diferentes indivíduos, com conteúdos discursivos de sentido semelhante [11].

O DSC é um processo subdividido em várias etapas e efetuado por meio de uma série de operações. A partir dos depoimentos, que consistem nas respostas obtidas nas entrevistas, os passos a seguir são: 
- No primeiro momento identificar as Expressões-Chave (E-Chs): pedaços, trechos ou mesmo transcrições literais do discurso, que revelam a essência do depoimento, que geralmente responde à pergunta. É com a matéria-prima das E-Chs que se constroem os DSCs.

- A partir das E-Chs são nominadas as IdeiasCentrais (ICs): um nome ou expressão que descreve de maneira mais sintética e precisa o sentido de cada um dos depoimentos analisados e de cada conjunto homogêneo de E-Chs. Não se trata de uma interpretação, mas uma descrição do sentido. É possível enquadrar os vários depoimentos em uma das ICs, no qual os depoimentos enquadrados na mesma IC são reputados equivalentes ou complementares, podendo consequentemente as E-Chs serem somadas.

- A soma das E-Chs que têm ICs de sentido semelhante ou complementar constroem os DSCs: um discurso-síntese redigido em primeira pessoa do singular com a finalidade do "eu" falar em nome de uma coletividade. Destaca-se que cada questão pode gerar um número diferente de posicionamentos que formam DSCs distintos ${ }^{[1]}$.

Para a análise do discurso foi utilizado o Quali Quanti Soft - SPI, softwvare proposto por Lefèvre \& Lefèvre [12], específico para o uso do DSC.

Para se ter o depoimento em sua integralidade, nesta parte da entrevista utilizou-se gravação magnética, com posterior transcrição fidedigna das respostas. Para as informações sobre as características da população, foi elaborado um banco de dados por meio do programa Excel. A análise foi realizada pelo mesmo programa, utilizando tabelas de contingências para descrição das frequências das variáveis.

No desenvolvimento desta pesquisa foram considerados os princípios éticos fundamentais que norteiam pesquisas envolvendo seres humanos, descritos e estabelecidos pela Resolução CNS 196/96 e suas complementares. O Termo de Consentimento Livre e Esclarecido foi apresentado aos gestores locais e, posteriormente assinado. $O$ presente projeto foi apresentado e aprovado pela Comissão de Ética em Pesquisa da Faculdade de Saúde Pública da Universidade de São Paulo, em 11 de novembro de 2005, protocolo № 1374 .

\section{RESULTADOS}

Em termos de caracterização da população (Tabela), observou-se que todos os entrevistados neste estudo pertencem ao gênero feminino. Os entrevistados apresentavam-se com idade de 25 a 56 anos, com maior prevalência de gestores na faixa de 40 a 60 anos e média de idade de aproximadamente 31 anos.

A respeito da escolaridade, observa-se, na Tabela, que todos os profissionais têm formação de nível superior em pedagogia ou letras, formação específica na área de educação. Verifica-se ainda que 4 dos 11 entrevistados possuíam pós-graduação na área. Entretanto, deve-se destacar que a maioria dos gestores começou sua formação com o curso magistério, curso técnico de nível médio onde se tem o primeiro contato com a área educacional.

Em relação aos filhos, a maioria dos entrevistados os possui. No que diz respeito à remuneração mensal verificou-se que 3 entre os 11 gestores informaram que é inferior a 5 salários míninos.

No tocante à primeira questão sobre a percepção dos gestores a respeito da alimentação saudável para crianças de 2 a 4 anos de idade identificou-se 5 ICs. Por limitações de espaço, não serão apresentados todos os DSCs desta questão.

IC 1 - Arroz, feijão e diversos tipos de legumes, verduras, frutas e carnes

DSC 1 - "Pra mim uma alimentação saudável deveria (ser) balanceada, ter o arroz o feijão, a carne, verduras, legumes, frutas e derivados de leite. Eu acredito que a alimentação da creche seja saudável, né? Elas têm o café da manhã, com café com leite, pão; têm o almoso que varia o cardápio e é seguido por nutricionista da prefeitura. Não descartar as frutas, é imprescindivel... Eu acho que deveria ter mais é a questão de variedade, que é uma coisa que en aprendi bastante. A criança aprende, conhece o mundo de várias maneiras, e uma delas é a parte de alimentação... E eu acho que a alimentaşão saudável (é) também a questão do visual, uma alimentação bonita”.

Esse discurso representou a opinião de $72,7 \%$ dos entrevistados e destaca os alimentos propriamente ditos, como o arroz, o feijão e as hortaliças, além da questão da variedade e visual da refeição.

IC 2 - Aquela que tivesse todos os nutrientes que elas precisam 
DSC 2 - "Uma alimentação que tivesse todos os grupos, como proteinas, os carboidratos, vitaminas, que precisa, né? E elas farem esta alimentação aqui, é feita diariamente, todo dia a gente faz a comida certinha. Por exemplo, a comida, eu acho que ela é balanceada porque vem a proteina, nós temos carne, frango, ovos e leite; vem o macarrão, o feijão, o arroz. que é do grupo dos carboidratos; e vem as verduras, frutas também. E o que é necessário para elas, que elas estão em fase de desenvolvimento".

No DSC $2(27,3 \%)$ mostra-se a importância dos nutrientes como proteínas, carboidratos e vitaminas para uma alimentação saudável.

IC 3 - Aquela quanto mais natural melhor, muitas verduras e legumes
DSC 3 - "A alimentação que desenvolva o crescimento deles. E o alimento saudável eu acho que é aquele quanto mais natural melhor. Muitas verduras, legumes, frutas... coisas que a criançada não gosta, né?...".

O DSC $3(18,2 \%)$ indica que para ter uma alimentação saudável é preciso ter tipos específicos de alimentos, verduras, legumes e frutas, alimentos considerados naturais.

As duas questões seguintes procuraram identificar as atividades realizadas com as crianças. A questão 2 procurou verificar aquelas realizadas no momento das refeições e nesta questão foram encontrados 4 ICs.

Tabela. Distribuição do número e proporção (\%) de diretores e coordenadores segundo sexo, idade, escolaridade, filhos e remuneração mensal. Município de Jandira, São Paulo. 2006.

\begin{tabular}{|c|c|c|c|}
\hline \multirow{2}{*}{ Variável } & \multirow{2}{*}{ Categorias } & \multicolumn{2}{|c|}{ Total } \\
\hline & & $n$ & $\%$ \\
\hline \multirow[t]{2}{*}{ Idade (anos) } & {$[20 ; 40)$} & 4 & 36,4 \\
\hline & {$[40 ; 60]$} & 7 & 63,6 \\
\hline \multirow[t]{2}{*}{ Escolaridade * } & 1 & 7 & 63,6 \\
\hline & 2 & 4 & 36,4 \\
\hline \multirow[t]{2}{*}{ Filhos } & Sim & 7 & 63,6 \\
\hline & Não & 4 & 36,4 \\
\hline \multirow[t]{2}{*}{ Remuneração mensal } & Até 5 salários ** & 8 & 72,7 \\
\hline & Mais de 5 salários ** & 3 & 18,3 \\
\hline
\end{tabular}

* Escolaridade: Categoria 1 - Magistério completo e Superior completo (Pedagogia ou Letras). Categoria 2 - Magistério ou Médio completo, Superior Pedagogia completo e Pós-graduação completo ou incompleto.

** Salário mínimo de 2006: R \$350,00. 
IC 6 - Por meio da conversa, sentando do lado, brincando, insistindo, oferecendo o alimento na boca

DSC 6 - "Olha, na verdade a gente tenta estimular que as crianças comam sempre aquele cardápio, nosso cardápio que vem da cozinha piloto que é elaborado pela nutricionista. No primeiro momento elas podem não aceitar, mas a gente está insistindo para que elas peguem o costume de estarem se alimentando, experimentando, porque às vezes elas falam 'não gosto', mas nunca experimentaram. Então, o que a gente procura fazer é ralar a cenoura no arroz, tentar fazer alguma coisa mais colorida para que eles comecem a comer. Até a coordenadora gosta de fazer brincadeirinhas na hora do almoço, fala 'olha, vamos comer isto daqui, é a comida do Huck, do Popeye para ficar forte', 'olha, a tia está comendo, vamos comer que é gostoso', entendeu? ... Aproveitando também que a criança, menina ou menino, já são vaidosos, a gente pega essa fraqueza da vaidade para mostrar a importância da comida, da alimentação, que cada alimento é bom para determinada parte do corpo. E é oferecida sempre a salada no prato, a criança precisa ver o alimento mesmo que ela não coma no momento, mas ela precisa ver, que um dia ela vai ter curiosidade de experimentar, ela pode até gostar. Então é respeitado, se ela não come, não vai empurrar na boca, mas é colocado no cantinho do prato.. tem que ter paciência e calma. (Mas) o importante é elas estarem comendo, tem algumas que não querem comer, ai se você for dar na boca e conversar, ela acaba até aceitando o alimento, mesmo que ela fala que não gosta".

Este discuso, DSC 6, mostra a dificuldade das crianças em aceitar o cardápio e as diferentes formas de estimulá-las durante o momento da refeição. Estas práticas são bem frequentes e foram relatadas por $72,7 \%$ dos gestores.

IC 7 - Misturando a comida e oferecendo outros alimentos

DSC 7 - "A maioria das crianças comem bem. São poucos os casos, tínhamos uma criança que só comia salada e uma outra que não aceitava sopas, nestes casos a gente procura oferecer aquilo que ela quer, né?... Então fazemos camuflado, ralamos a cenoura, a beterraba. Então nós picamos bem pequenininho $e$ colocamos no feijão, a mandioquinha, a abóbora, a couve, o espinafre, também colocamos no arroz: Ela acaba comendo sem perceber que está se alimentando adequadamente. Se a criança não quer também não vai (forçar), mas como a gente não pode deixar a criança sem comer, então é feito sopa bem equilibrada e é oferecida. (Ou) tentamos mudar, oferecendo de outra forma, trocando o alimento, por exemplo, se ela não gosta de leite puro, a gente tenta colocar o chocolate, sempre insistindo na maneira certa até a criança se adaptar, entendeu?".
Nesse discurso, compartilhado por 36,4\% dos gestores, destaca-se a utilização de recursos como a camuflagem de alimentos para melhorar a aceitação alimentar. Eles acreditam que é importante que as crianças comam tudo o que é oferecido pelo fato de ser um cardápio elaborado por nutricionista.

IC 8 - Conversando com os pais, é um trabalho em conjunto

DSC 8 - "É assim, tem criança que chega na creche e não está acostumada a comer arroz e feijão, ela quer só leite, já chega pedindo mamadeira, tanto que na primeira reunião com os pais nós conversamos para eles não estarem trazendo. Então, a criança tem que aprender a se alimentar no copinho ou na canequinha, então a gente pede para os pais não trazerem alimento nenhum, bolacha, mamadeira, nada!..Se a gente vê que a criança não aceita realmente, nós falamos com os pais para levar ao médico porque tem criança que tem problema de refluxo, tem criança que não pode comer isso, não come uma outra alimentação, mas isso os pais vem e já nos avisam”.

Verifica-se nesse discurso (18,2\%) uma discussão sobre a dificuldade de aceitação do cardápio da creche referindo esse fato a hábitos alimentares anteriores à creche, e nesse contexto a necessidade de se atuar junto com os pais para melhorar a alimentação das crianças.

IC 9 - Incentivando todas, aquelas que já têm o hábito de se alimentarem até aquelas que não têm

DSC 9 - “... gente incentiva as crianças a comer, principalmente verduras e legumes que é uma coisa que elas não gostam. A gente procura incentivar todas, mesmo aquelas que já têm o bábito de se alimentar e até aquelas que não têm esse bábito. E claro que têm umas que comem mais e outros comem menos, tem a questão da repetição, então a gente também dá repetição para elas, mas também medindo um pouco, nada de 3 vežes na refeição, tem umas que até pedem”.

O DCS 9 (18,2\%) foi o único discurso em que os gestores mostraram preocupação com todas as crianças, e não apenas com aquelas que apresentam recusa alimentar.

A questão seguinte complementa as atividades realizadas com as crianças e, especificamente, aquelas reconhecidas pelos gestores como promotoras da alimentação saudável. Optou-se por apresentar apenas um discurso.

IC 11 - Teria que começar na sala, mostrando os alimentos para eles, trazendo os alimentos para eles experimentarem 
DSC 11 - "Olha, uma coisa legal que nós fizemos é estar levando a criança para fazer salada de frutas, preparando bolos, um suco de laranja com beterraba... Deixar ela ter contato com o alimento, manusear, lavar, cortar, fazer uma salada. Estar mostrando para elas como é gostoso estar comendo aquilo que elas fizeram. E ai estar falando quais são os beneficios para a saúde delas. Eu gosto muito de experimentar e falar 'olha, é gostoso, a tia tá comendo', e eles (dizem) 'tia, é gostoso? E bom? Eu vou comer também!'... E uma outra coisa que nós já fizemos ... foi a feira, colocando alimentos mesmo, cenoura, abóbora, folhas e pedir para elas comprarem, mostrando para elas qual é a importância destes alimentos... Também na sala, a gente faz modelagem com massinha. Então, quando vai pintar um desenho elas sabem o que é, da massinha amarela eles falam 'ah, eu fir uma banana'. Nós fizemos também bichinhos com os alimentos., com chuchu, girafa de cenoura, aí nós fizemos uma exposição, tiramos fotos. $\mathrm{Na}$ bora que a gente vai oferecer a laranja, a gente conversa com elas vocês lembram do filme da laranja? Que o bebê não comeu a laranja e ficou dodói e ficou com gripe? Dentro da linguagem da criança, tá? Então, procuraria trazer o concreto para elas, fazer assim o faz de conta para estar estimulando e depois partir para o próprio alimento mesmo...".

Esse discurso mostra a variedade de ações que os gestores verbalizam como possibilidades de sucesso para a promoção das práticas alimentares saudáveis. Contribuíram para esse discurso 63,7\% dos entrevistados.

Uma das propostas que vem ganhando força em relação as atividades realizadas pelos educadores nas escolas é a melhoria da qualidade da formação inicial e continuada destes profissionais. Para verificar a situação destes educadores infantis, foi elaborada a questão 4 $\mathrm{Na}$ sua opinião, os monitores desta creche estão capacitados para trabalhar com atividades de alimentação saudável com as crianças? Fale um pouco sobre isso.

IC 16 - Não totalmente, falta experiência e conhecimento, não possuem formação adequada

DSC 16 - "Capacitados totalmente não... porque muitos monitores não são educadores, não estudaram para isso. Tem monitoras aqui que nunca trabalharam na área... que tiveram muita dificuldade. Então elas fariam o que elas sabiam da casa delas... do jeito que criavam os filhos elas fariam aqui. Mas tem que ter bastante incentivo e tem que estar sempre junto, dar um apoio... porque às vezes elas estão fazendo a coisa certa mas não sabem, estão fazendo por instinto, né? Mas nesses anos que têm tido capacitação, elas estão melhorando muito, até estão buscando mais. (Antes), não era dado enfoque a este tipo de atividade (alimentação) com elas, de conteúdo. Não digo que elas não saibam fazer isso, mas en acho que vai ter que ter um cuidado especial de passar para elas a importância disso, né? Não só falar sobre alimentação, mas elas sentivem uma responsabilidade que podem estar mudando esse bábito alimentar das criancas. Acho que precisaria sim estar capacitando, orientando. Tem o programa, tem o planejamento que a gente fala o que elas vão fazer para estar desenvolvendo este trabalho de alimentasão e também (são) orientadas. Então, eu acho que elas ainda não estão (capacitadas para trabalharem), com as atividades (em alimentação), elas estão desenvolvendo ainda as babilidades, tá? Eu acho que realmente precisa de formação sempre, sempre".

Verificou-se que 63,6\% dos gestores não consideravam os educadores capacitados para promover a alimentação saudável com as crianças, alegando deficiência na formação.

\section{DISCUSSÃO}

Quanto à caracterização da população de estudo, foi observado que todos os entrevistados pertenciam ao sexo feminino. Este resultado pode ser explicado pelo fato da função social de educar crianças, principalmente as pequenas, ainda estar muito ligada ao gênero feminino. A trajetória do profissional que atua na educação infantil reforçou a imagem da mulher como sendo "naturalmente" habilitada para o cuidado com a criança, pensamento fortemente ligado à maternidade, da mulher como educadora nata e em detrimento de uma formação profissional adequada [13].

Considerando as percepções sobre o significado de alimentação saudável, os gestores citaram grande parte dos itens que a compõe, como variedade, quantidade, qualidade adequada. "Pra mim uma alimentação saudável deveria (ser) balanceada, ter o arroz, o feijão, a carne, verduras, legumes, frutas e derivados de leite...". "... Eu acho que deveria ter mais é a questão de variedade...". Porém, não foram contempladas questões como procedência, refeições realizadas em ambientes calmos, satisfação das necessidades emocionais e sociais como os definidos por Philippi et al. [1].

É importante destacar que a Educação Infantil do município de Jandira integra o Programa Nacional de Alimentação Escolar (PNAE), que é um programa do Fundo Nacional para o Desenvolvimento da Educação (FNDE) do Ministério da Educação do Governo Federal e tem por objetivo "garantir a alimentação saudável e adequada, com o uso de alimentos variados, seguros, que respeitem a cultura e as tradições alimentares, aos alunos da educação infantil (creches e pré-escola) e do ensino fundamental, por meio da transferência de recursos financeiros" [3]. Seu 
objetivo é atender às necessidades nutricionais dos alunos durante sua permanência em sala de aula, contribuindo para o crescimento, o desenvolvimento, a aprendizagem e o rendimento escolar dos estudantes, bem como a formação de hábitos alimentares saudáveis [3].

Verifica-se, pois, que as características consideradas pelos gestores acerca da alimentação saudável ainda está restrita aos aspectos biológicos da alimentação. Sem a inclusão das funções sociais da mesma.

Para formar os hábitos saudáveis é importante, segundo Proença \& Poulain [14], que se observe as funções sociais da alimentação, já que a alimentação participa da construção e da manutenção das identidades sociais no sentido de que o ser humano come não só os nutrientes, mas também come os sinais e os símbolos daquilo que os alimentos representam. Assim, crianças podem consumir alimentos que estão carregados de significados, ou seja, embora fisiologicamente possa comer muitas e diferentes substâncias (vegetais, animais e minerais), ele comerá somente aquilo que reconhece como alimento. Para Garcia [15], o comportamento alimentar inclui o que comemos, como e com o que comemos, com quem comemos, onde comemos, quando comemos, por que comemos, em quais situações comemos, o que pensamos e sentimos em relação ao alimento. E é dessa forma que significados são incorporados à alimentação.

No que se refere às práticas realizadas no ambiente escolar fica evidente dos depoimentos a função importante do educador para estimular, de algumas maneiras, a ingestão dos alimentos oferecidos e muitas vezes rejeitados.

As diretrizes do PNAE vêm sendo implementadas a fim de estabelecer ações que incentivem o espaço escolar como ambiente para a educação nutricional e promoção da alimentação saudável de crianças, contribuindo para a formação de hábitos alimentares saudáveis [2]. Essas questões têm de ser aprendidas, reforçadas, concretizadas e implantadas no cotidiano da vida escolar e em casa. Destaca-se entre as ICs apresentadas, aquela referente às atividades que envolvam os pais dos estudantes, correspondente ao DSC 8. Esta atividade vai ao encontro da diretriz III, que cita a necessidade de informar os pais sobre a alimentação na escola.

É necessário realizar ações que possam ser compartilhadas com o núcleo familiar, procurando organizar estratégias que possibilitem socializar conhecimentos e refletir em conjunto com as famílias a respeito dos procedimentos desenvolvidos com as crianças. Cabe à creche fazer um trabalho complementar e compartilhado e não de substituição à família, pois ambas possuem responsabilidades e papéis específicos frente à educação e ao cuidado com a criança [16].

Ao abordar atividades de educação alimentar como possibilidades de sucesso para a promoção das práticas alimentares saudáveis, os gestores destacaram várias estratégias que atendem as do PNAE como a aplicação da educação alimentar e nutricional no processo de ensino e aprendizagem e a promoção de ações educativas. Pode-se observar que há um reconhecimento da importância de atividades com tema saúde e educação alimentar, mas aparentemente esse tema ainda não está incorporado ao projeto pedagógico. Observou-se que as atividades inseridas são informais e ficam a critério dos educadores, de que forma e em que momento elas serão apresentadas.

Verifica-se que as estratégias utilizadas e apontadas no DSC 11, referente a mostrar e deixar que as crianças manuseiem os alimentos em sala de aula está relacionada à diretriz VII, que destaca a importância em auxiliar o serviço de alimentação escolar na divulgação de opções saudáveis.

No relatório de avaliação do PNAE de 2004, foi relatado que das 169.597 escolas que participaram da avaliação, apenas 38,3\% informaram realizar atividades de educação alimentar e nutricional. Entre as atividades realizadas pelas escolas brasileiras, destacamse: cultivo de hortas e pomares $(11,0 \%)$; valorização de hábitos alimentares locais $(19,4 \%)$; combate ao desperdício de alimentos (26,9\%); aulas de bons hábitos alimentares $(32,4 \%){ }^{[17]}$.

Destaca-se um distanciamento das diretrizes do PNAE na questão 4, que apresenta a opinião dos gestores sobre a capacitação dos monitores e professores. A maioria dos gestores não acredita que os professores tenham capacitação suficiente para desenvolver atividades com alimentação. A falta de recursos humanos habilitados pode ser um fator limitante para o sucesso de programas como esse.

Nos depoimentos nada foi mencionado sobre a troca de experiências entre as escolas para fortalecer os trabalhos realizados e incentivar o desenvolvimento de novos. Essa troca é atada à diretriz VIII do PNAE, que estabelece que para atingir uma alimentação 
saudável no ambiente escolar é importante divulgar a experiência de alimentação saudável para outras escolas, trocando informações e vivências.

Nesse sentido, Vieira ${ }^{[18]}$ sugere que para ter um ambiente favorável para promover hábitos saudáveis é necessária uma aproximação dos responsáveis pelas políticas públicas com os gestores do município e das instituições educacionais. Eles devem atuar juntos, colocar em prática o programa, identificar pontos positivos e negativos, e assim divulgar as atividades de sucesso e as dificuldades, para trazer sempre melhorias aos programas.

\section{CONSIDERAÇÕES FINAIS}

A partir das informações coletadas nos depoimentos dos entrevistados, foi identificado o entendimento dos gestores da educação sobre a questão da promoção da alimentação saudável para crianças em ambiente escolar.

Verificou-se a presença de deficiências nos conceitos, nas atitudes, nas práticas e sobre alimentação infantil entre os profissionais que trabalham com o crescimento, desenvolvimento e educação das crianças da rede de creches municipais de Jandira. Isso porque a alimentação deve ser percebida como uma atividade pedagógica e de forma interdisciplinar, ou seja, em todos os seus aspectos, e não somente de uma forma biológica e contextualizada apenas na rotina alimentar.

Foi detectada a necessidade de políticas estruturais, específicas e locais, que promovam a alimentação e hábitos alimentares saudáveis das crianças no ambiente escolar, começando por incorporar ao projeto pedagógico o tema e desenvolvêlo com toda a equipe escolar. A aproximação dos educadores com os demais profissionais da escola, como os cozinheiros, auxiliares de cozinha e equipe da alimentação escolar (nutricionista, técnico em nutrição e dietética) sequer foi mencionada. Muitos destes profissionais possuem formação específica sobre os conteúdos de nutrição e poderiam colaborar na elaboração do próprio projeto político pedagógico da unidade educacional. O PNAE tem estimulado a participação dos profissionais da alimentação escolar para atuarem como promotores de hábitos alimentares saudáveis, mas é possível verificar esta lacuna entre aqueles que cuidam da alimentação e os que cuidam da educação.

Verifica-se também a necessidade de ampliar a abordagem do tema alimentação entre os profissionais da área da educação. Destaca-se que a experiência prática é insuficiente, assim, faz-se necessário a promoção de cursos de capacitação que discutam o tema alimentação saudável para as crianças com os educadores. Do mesmo modo, mostra-se evidente a importância deste tema na formação de profissionais da área da educação. A partir de ações como essas é possível planejar atividades com o tema, evitando as improvisações descontextualizadas.

Os desafios a serem superados ainda são muitos, como a falta de recursos específicos para a educação alimentar e nutricional e a falta de percepção dela como ação prioritária pelos gestores públicos. Entretanto, para o município de Jandira, os resultados auxiliarão a sugerir intervenções neste grupo a fim de minimizar deficiências que tragam repercussões futuras no estilo de vida da criança que ainda está em formação dos hábitos alimentares.

Portanto, destaca-se a importância da inserção do tema alimentação e nutrição com ênfase na alimentação saudável e na promoção da saúde no ambiente escolar, pois a escola é reconhecida como um espaço propício à formação de hábitos saudáveis. Dessa forma, esse tema aparece no contexto escolar com uma função pedagógica, e deve ser inserido no currículo da instituição.

\section{REFERÊNCIAS}

[1] Philippi ST, Colucci ACA, Cruz ATR, Ferreira MN, Coutinho RLR. Alimentação saudável na infância e na adolescência. In: Silva MV, organizador. Curso de atualização em alimentação para professores de rede pública de ensino. Piracicaba: Escola Superior de Agricultura Luiz de Queiroz (Esalq); 2000. p.46-56.

[2] Focesi E. Educação em Saúde na Escola: o papel do professor. Rev Bras Saude Esc. 1990;1(2):4-8.

[3] Brasil. Portaria Interministerial no 1.010, de 08 de maio de 2006. Institui as diretrizes para a Promoção da Alimentação Saudável nas Escolas de educação infantil, fundamental e nível médio das redes públicas e privadas, em âmbito nacional. Diário Oficial da União, Brasilia, 09 maio 2006. Seção 1, p. 70.

[4] Assao TY. Percepções e práticas do educador acerca da alimentação infantil em creches públicas do Município de Jandira, São Paulo [dissertação]. São Paulo: Faculdade de Saúde Pública, Universidade de São Paulo; 2007.

[5] Marinho FCM. Reflexão sobre a percepção dos profissionais da saúde e da educação sobre a alimentação saudável. In: Resumos do Simpósio de Iniciação Científica da Universidade de São Paulo. Ribeirão Preto, São Paulo; 2007. 
[6] Reis MGFA. O compromisso político-social do diretor como educador [dissertação]. São Carlos: Programa de Pósgraduação em Educação Especial, Universidade Federal de São Carlos; 2000.

[7] Minayo MCS. O desafio do conhecimento: pesquisa qualitativa em saúde. São Paulo: Hucitec; 2004.

[8] Lefèvre F, Lefèvre AMC, Teixeira JJV. O discurso do sujeito coletivo: uma nova abordagem metodológica em pesquisa qualitativa. Caxias do Sul: EDUCS; 2000.

[9] Prefeitura do Município de Jandira [homepage na internet]. São Paulo; 2007 [acesso em 15 abr 2008]. Disponível em: http://www.jandira.sp.gov.br

[10] Instituto Nacional de Estudos e Pesquisas Educacionais Anísio Teixeira. Censo Escolar 2005 [acesso em 6 fev 2008]. Disponível em: http://www.inep.gov.br

[11] Lefèvre F, Lefèvre AMC. Discurso do sujeito coletivo: um novo enfoque em pesquisa qualitativa (desdobramentos). Caxias do Sul: EDUCS; 2003.

[12] Lefèvre F, Lefèvre AMC. Depoimentos e discursos: uma proposta de análise em pesquisa social. Brasília: Líber livros; 2005.
[13] Arce A. Documentação oficial e o mito da educadora nata na educação infantil. Cad Pesq. 2001;(113):167-184.

[14] Proença RPCP, Poulain J. Sociologia da alimentação: um enfoque na compreensão dos comportamentos alimentares. In: Taddei JAAC, coordenador. Jornadas científicas do Núcleo Interdepartamental de Segurança Alimentar e Nutricional. Barueri: Manole; 2007. p. 165-178.

[15] Garcia RWD. A comida, a dieta, o gosto: mudanças na cultura alimentar urbana [tese]. São Paulo: Instituto de Psicologia, Universidade de São Paulo; 1999.

[16] Amaral MFM, Morelli V, Pantoni RV, Rossetti-Ferreira MC. Alimentação de bebês e crianças pequenas em contextos coletivos: mediadores, interações e programações em educação infantil. Rev Bras Cresc Desenv Hum. 1996;6(1/2): 19-33.

[17] Programa Nacional Alimentação Escolar. Avaliação do Programa Nacional de Alimentação Escolar - Censo Escolar 2004. Brasília; 2007.

[18] Vieira MNCM, Ferriani MGC, Gomes R, Santos GVB, Marchi EMM.Gestão de um Programa de Alimentação Escolar em um Município Paulista. Segurança Alimentar e Nutricional. 2008;15(1):29-48. 